\title{
ESTUDO SOBRE OS TIPOS DAS ÁGUAS DO AQUÍFERO SERRA GERAL, NO MUNICÍPIO DE MARECHAL CÂNDIDO RONDON - PR
}

\author{
GROUNDWATER TYPES STUDY OF SERRA GERAL AQUIFER \\ IN MARECHAL CÂNDIDO RONDON-PR
}

\author{
Gustavo Barbosa Athayde ${ }^{1}$, Camila de Vasconcelos Müller ${ }^{1}$, \\ Ernani Francisco da Rosa Filho ${ }^{2}$ e Eduardo Chemas Hindi ${ }^{2}$
}

\begin{abstract}
RESUMO
O Aquíf́ero Serra Geral é formado pelos basaltos da Fm. Serra Geral, destacando-se como o mais importante aqüífero do Estado do Paraná. As águas do Aqüífero Serra Geral são utilizadas para abastecimento público, e em menor volume, para indústrias, hotéis e irrigação. O objetivo deste trabalho foi classificar o tipo químico das águas subterrâneas, bem como verificar a possibilidade de utilização para irrigação. As amostras de água foram coletadas em 34 pontos e analisadas para determinar a concentração dos íons principais (cálcio, magnésio, sódio, potássio, cloreto, sulfato e nitrato, entre outros) e total de sólidos dissolvidos. Alcalinidade, temperatura, $\mathrm{pH}$ e condutividade foram medidas em campo. Foram classificados sete tipos de água utilizando o diagrama de Piper para representá-los graficamente. Predominam águas bicarbonatadas cálcicas, destacando a ocorrência de águas carbonatadas sódicas e sulfatadabicarbonatada sódicas. Estes últimos tipos químicos sugerem a existência de mistura de águas com o Aquífero Botucatu, subjacente ao Aquiífero Serra Geral. De uma maneira em geral as águas não possuem restrições para o consumo in natura ou utilização para irrigação. Ressalta-se que em alguns pontos, as amostras são restritivas devido aos teores de sódio, cloreto, $\mathrm{pH}$ e condutividade.
\end{abstract}

Palavras-chave: Aqüífero Serra Geral, Classificação Hidroquímica e Marechal Cândido Rondon

\begin{abstract}
The Serra Geral Aquifer is constituted by basalts and associated rocks, fracture type, and very important (mainly exploited) as a plublic supply and alternatives uses like industry and irrigation in the State Paraná. The aim of this research is defined the water types using the Piper diagram. Ground water samples were collected in 34 points and analyze for the major ions (calcium, magnesium, sodium, potassium, chloride, sulfate and nitrate among others) and total dissolveld solids. Alkalinity, temperature, $\mathrm{pH}$ and specific conductance were measured in the field. The major water type was $\mathrm{Ca}-\mathrm{HCO}_{3}$; types like: $\mathrm{Na}-\mathrm{CO}_{3}$ and $\mathrm{SO}_{4}-\mathrm{HCO}_{3}$ were associeted with the Botucatu Aquifer. The results of this research show that the SGA is strategic for public water supply and can be used, in extreme conditions to irrigation.
\end{abstract}

Keywords: Serra Geral Aquifer, Hidrochemical Classification and Marechal Cândido Rondon

\section{INTRODUÇÃO}

O Aquífero Serra Geral (ASG) é um dos mais importantes aqüíferos do Estado do Paraná, em função de sua área de abrangência e principalmente, de seu potencial para abastecimento público. Destaca-se também a qualidade de suas águas para outros fins, como irrigação, uso industrial, rede hoteleira, dentre outros.

A área de estudo abrange o município de Marechal Cândido Rondon (MCR), localizado na região oeste do Estado do Paraná, o qual possui área de $747.11 \mathrm{~km}^{2}$. A agricultura é a principal atividade econômica no município, setor que vem acumulando prejuízos devido às estiagens ocorridas nas últimas safras. Segundo IBGE a população estimada do município de Marechal Cândido Rondon em 2006 é 45.369 habitantes. O abastecimento público é realizado pelo Serviço Autônomo de MCR, o qual utiliza predominantemente poços tubulares profundos que captam o ASG. Soma-se aos poços que captam o ASG em MCR, um poço tubular desativado que capta o Aqǘf́ero Botucatu, com profundidade total de 920 metros, deste total, 795 metros correspondentes a espessura da Fm. Serra Geral e 125 metros perfurados no Aqüífero Botucatu.

Amostras de água coletadas nos poços tubulares profundos foram utilizadas para classificação hidroquímica pelos íons predominantes, bem como verificar a possibilidade de uso destas águas na irrigação.

Dentre os poços tubulares que captam o Aqüífero Serra Geral em MCR, verifica-se que alguns apresentam características químicas semelhantes ao Aqüífero Botucatu (Guarani), em sua área de confinamento, no Estado do Paraná, o que sugere a existência de conectividade hidráulica entre os aqüíferos.

\footnotetext{
${ }^{1}$ UFPR - alunos da Pós-graduação em Geologia (camilavmuller@yahoo.com.br;e (gustavo_athayde@yahoo.com.br).

${ }^{2}$ UFPR-DEGEOL-LPH - Laboratório de Pesquisas Hidrogeológicas (ernani@ufpr.br); (hindi@ufpr.br)
} 


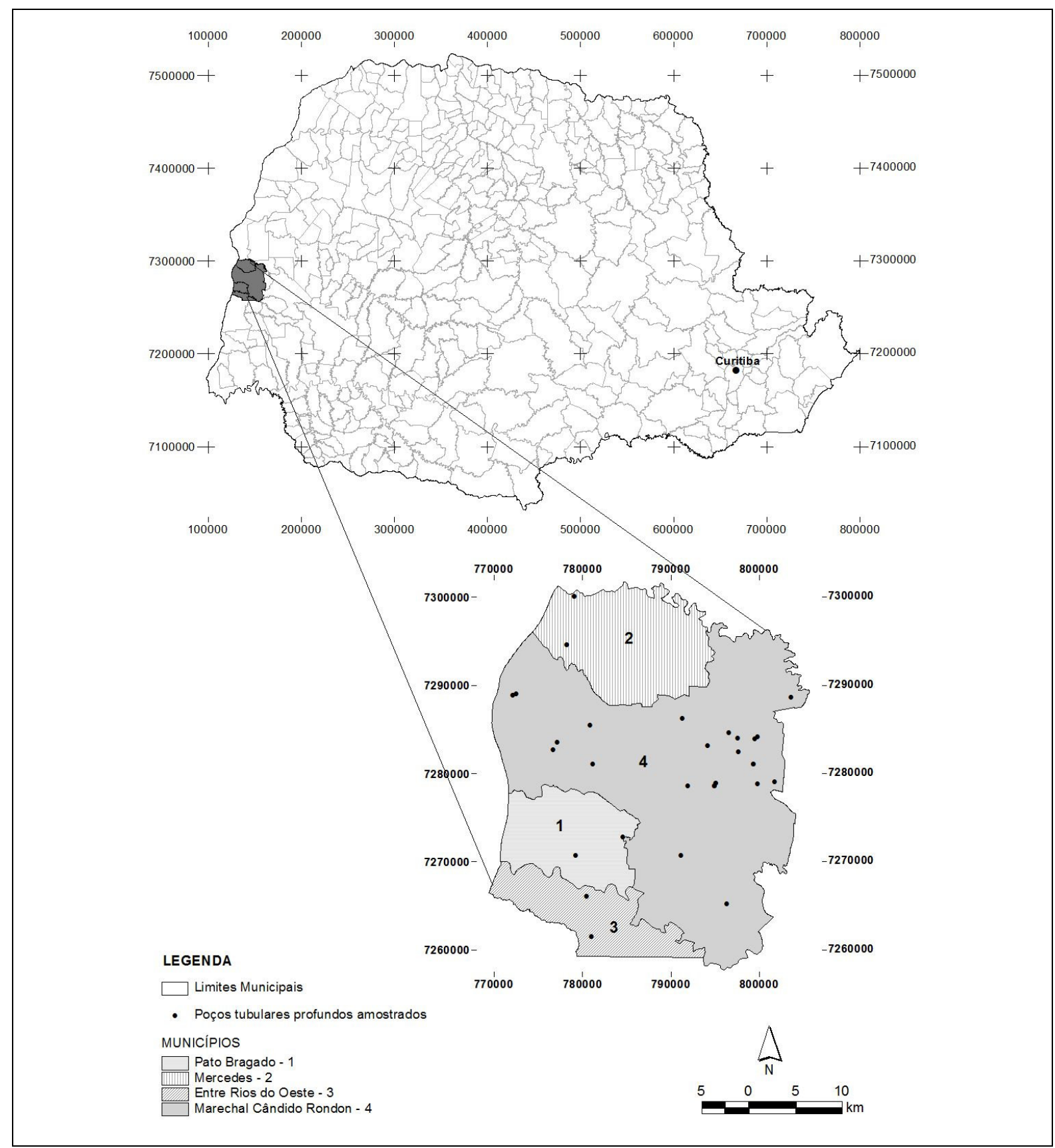

Figura 1 - Mapa de localização da área de estudo.

Figure 1 -Localization map of the study area.

\section{LOCALIZAÇÃO DA ÁREA}

Marechal Cândido Rondon localiza-se no extremo oeste paranaense, fronteira com 0 Paraguai, as margens do reservatório de ITAIPU BINACIONAL (Figura 1).

\section{OBJETIVOS}

O objetivo deste trabalho é analisar a tipologia das águas coletadas em 34 poços tubulares profundos, situados próximos e no município de Marechal Cândido Rondon, com a finalidade de classificação hidroquímica e possibilidade de aproveitamento das águas para irrigação.

\section{MATERIAL E MÉTODOS}

Os dados cartografados utilizados estão projetados em UTM - Fuso 21 Sul, datum SAD 69. As rotinas de processamento foram realizadas com os programas: Rockworks; Qualigraf e Statistica 7.

Para confecção da base cartográfica foram utilizados mapas e imagens fornecidas pela ITAIPU - BINACIONAL. Os dados, de consulta restrita à ITAIPU, referem-se ao mapeamento de detalhe realizado em toda BPIII, fornecidos no formato shapefile, contendo: carta de drenagem, carta plani-altimétrica e carta com as principais vias de acesso. 
Para classificar os tipos de água existentes e verificar a aplicação destas na irrigação foram realizados os seguintes estudos: classificação hidroquímica pelos íons predominantes e diagrama da relação entre adsorção de sódio e condutividade elétrica da água (RAS).

$\mathrm{Na}$ classificação do quimismo da água subterrânea do ASG foram utilizadas 34 análises físico-químicas de água de poços tubulares profundos. As amostras foram coletadas em campo, onde também foram determinados os parâmetros alcalinidade, $\mathrm{pH}$, condutividade elétrica e temperatura. Após a coleta as amostras foram armazenadas em caixas com isolante térmico, refrigerada, mantendo-se a temperatura das amostras em torno de $4^{\circ} \mathrm{C}$.

Os laudos analíticos do Laboratório de Pesquisas Hidrogeológicas (LPH) apresentam o rol mínimo de 32 parâmetros. A consistência e qualidade dos dados foram avaliadas pela Diferença de Balanço Iônico (DBI), que mede a diferença relativa entre as concentrações de cátions e ânions expressa em meq/L. As amostras coletadas apresentam DBI inferior a $10 \%$, com resultado médio de $3 \%$.

Os resultados e concentrações obtidas nos laudos físico-químicos foram submetidos a análises estatísticas univariadas para determinação de parâmetros descritivos e do tipo de distribuição dos dados.

A classificação química da água foi feita pelo método de íons dominantes, utilizando-se o diagrama de Piper (PIPER, 1945), para representação dos resultados.

A avaliação da qualidade da água para fins de irrigação foi realizada pela aplicação do diagrama que relaciona a razão de adsorção de sódio (RAS) com a condutividade elétrica da água, desenvolvido pelo U.S. Salinity Staff (1954), indicando os riscos potenciais de sódio e salinidade.

Neste diagrama, o risco de sódio é indicado no eixo das ordenadas em quatro classes de risco: baixo, médio, forte e muito forte. $\mathrm{O}$ risco de salinidade está indicado no eixo das abscissas em seis classes de risco: nulo, baixo, médio, alto, muito alto e excepcionalmente alto. Os campos definidos pela intercessão dessas classes definem se a água é adequada ou não para irrigação.

\section{O AQÜÍFERO SERRA GERAL NO ESTADO DO PARANÁ}

Dentre as unidades aqüíferas existentes no Estado do Paraná o aqüífero denominado Serra Geral corresponde aos basaltos e derivados da Formação Serra Geral.

A Formação Serra Geral (WHITE, 1906), refere-se à província magmática relacionada aos derrames e intrusivas que recobrem $1,2 \times 10^{6} \mathrm{~km}^{2}$ da Bacia do Paraná, abrangendo toda a região centro-sul do Brasil e estendendo-se ao longo das fronteiras do Paraguai, Uruguai e Argentina.

Os basaltos continentais da "Província Magmática do Paraná" definida por Peate et al., (1992) representam grandes volumes de magma gerados em períodos relativamente curtos de tempo. Rápidas taxas de geração de magma indicam fusão parcial, em resposta a eventos extensionais, associados a abertura do Atlântico Sul. Os derrames possuem textura microcristalina, estrutura maciça e vesicular e/ou amigdalóide, intenso fraturamento, bem como esfoliações esferoidais. Segundo Melfi et al., (1988) as suítes vulcânicas são essencialmente sub-horizontais, com um mergulho médio de $5^{\circ}$ em direção ao interior da Bacia do Paraná. Entretanto, os fluxos basais podem apresentar inclinações excepcionalmente altas relacionadas à topografia irregular do embasamento.

Segundo dados da Superintendência de Desenvolvimento de Recursos Hídricos e Saneamento Ambiental - SUDERHSA (2005), o ASG é o aqüífero com maior número de poços outorgados no Estado do Paraná, aproximadamente 5900 poços.

A maior freqüência das entradas de água nos poços perfurados na Fm. Serra Geral, no Estado do Paraná, está localizada até os $110 \mathrm{~m}$ de profundidade, nessa faixa as vazões variam de 1 a $70 \mathrm{~m}^{3} / \mathrm{h}$ (ROSA FILHO et al., 1987).

A circulação de águas dá-se em meio fraturado, onde além das fraturas tectônicas, ocorrem outros tipos de descontinuidades importantes para a circulação e armazenamento da água, representadas por fraturas de resfriamento que podem ser verticais (disjunções colunares) ou sub-horizontais. Segundo Fernandes et al. (2006) a maior parte do fluxo no ASG fica limitado às fraturas sub-horizontais e a algumas estruturas tectônicas sub verticais.

É consenso entre muitos autores que predomina a tipologia química bicarbonatada cálcica nas águas do Aqüífero Serra Geral, no Estado do Paraná. Estudos de Buchmann Filho (2002) e Bittencourt et al., (2003) realizados na Bacia do Rio Piquiri (situada à nordeste de 
MCR) indicam que o bicarbonato é o ânion mais abundante nessas águas. A concentração média é de 48,95 mg/L, com uma variação de 6 e 127 $\mathrm{mg} / \mathrm{L}$. Em $82 \%$ das amostras, a concentração é inferior a $75 \mathrm{mg} / \mathrm{L}$. Esta é uma característica bastante comum em se tratando de águas continentais relativamente diluídas. No mesmo trabalho, descreve-se que o bicarbonato é diretamente influenciado pelo equilíbrio do sistema $\mathrm{CO}_{2}-\mathrm{H}_{2} \mathrm{O}$ vigente nas áreas próximas à recarga, também pelas reações de hidrólise dos silicatos das efusivas.

Segundo Bittencourt et al., (2003) os principais processos que condicionam $\mathrm{o}$ quimismo das águas do Aquífero Serra Geral na bacia hidrográfica do rio Piquiri são: dissolução dos basaltos e equilíbrio com minerais secundários; além de misturas com águas de aqüíferos sotopostos (aqüífero Guarani principalmente).

Uma abordagem regional realizada por Rosa Filho; Hindi (2006) descreve para o ASG, no Estado do Paraná, teores de sólidos totais dissolvidos entre 100 e $150 \mathrm{mg} / \mathrm{L}, \mathrm{pH}$ entre 6,6 a 7,2 e dureza em torno de $40 \mathrm{mg}-\mathrm{CaCO}_{3} / \mathrm{L}$. O teor médio de cálcio é $9 \mathrm{mg} / \mathrm{L}$. As concentrações de magnésio variam de 3,5 a $6,5 \mathrm{mg} / \mathrm{L}$, as de sódio, entre 1,2 a $3,7 \mathrm{mg} / \mathrm{L}$, e as de potássio, entre 1,5 a $3 \mathrm{mg} / \mathrm{L}$. O teor médio de bicarbonato é $38 \mathrm{mg} / \mathrm{L}$, o de cloreto, $1,5 \mathrm{mg} / \mathrm{L}$ e o de sulfato, $2,5 \mathrm{mg} / \mathrm{L}$.

Posicionado abaixo do Aqüífero Serra Geral, sem afloramentos na área de estudo, ocorre o Aqüífero Botucatu (Guarani). Este aquifero, em MCR, não é utilizado no abastecimento público em função da salinidade de suas águas.

\section{CLASSIFICAÇÃO HIDROQUÍMICA DO ASG NO MUNICÍPIO DE MCR}

Para avaliar a tipologia e a variação do quimismo da água subterrânea do Aqüífero Serra Geral foram utilizadas 34 análises físicoquímicas de água de poços tubulares profundos.

As amostras foram coletadas nos dias $18 \mathrm{e}$ 19 de novembro de 2009, nos poços tubulares profundos que captam o ASG situados nos municípios de Marechal Cândido Rondon, Mercedez, Pato Bragado e Entre Rios do Oeste, todos pertencentes ao Estado do Paraná.

Dentre os poços estudados podem ser classificados sete tipos principais de águas: bicarbonatada cálcica $(43,6 \%)$; bicarbonatada sódica $(17,9 \%)$; bicarbonatada sódica-cálcica $(12,8 \%)$; bicarbonatada cálcica-sódica $(7,7 \%)$; bicarbonatada-carbonatada sódica (7,7\%); carbonatada sódica $(5,1 \%)$; sulfatadabicarbonatada sódica $(5,1 \%)$.

A distribuição percentual dos tipos de água para o conjunto de amostras analisado está apresentada na figura 2 .

A figura 3 apresenta o diagrama de Piper (1945) para todo o conjunto de amostras. Neste diagrama observa-se principalmente a tendência das águas bicarbonatadas cálcicas migrarem para o campo correspondente ao tipo de água bicarbonatada sódica.

Predomina nas águas do ASG, no município de MCR e fronteiriços o tipo químico bicarbonatada cálcica. Este fato corrobora com os resultados obtidos por diversos autores como o tipo químico predominante deste aquifero no estado do Paraná.

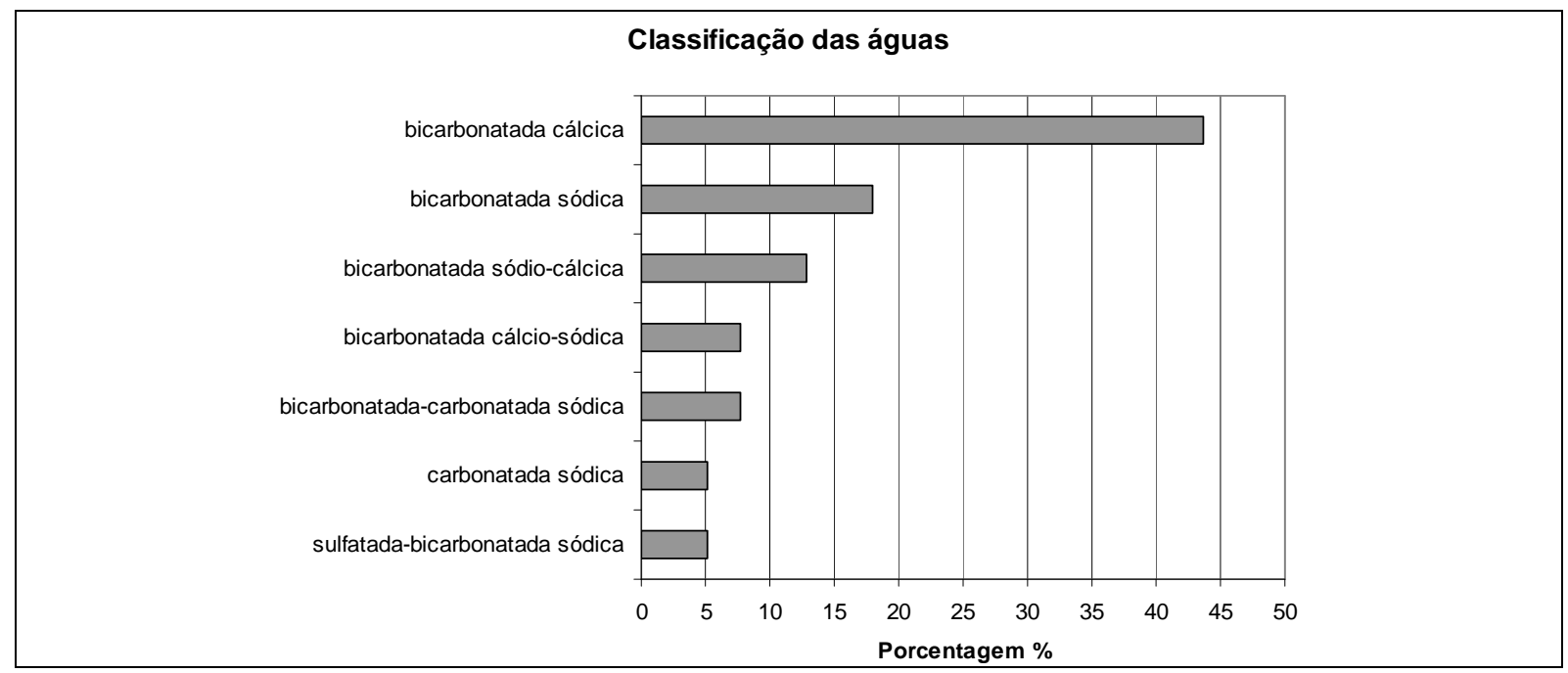

Figura 2 - Distribuição percentual das classes de água com base nas análises físico-químicas das amostras coletadas nos poços tubulares profundos.

Figure 2 - Percentage distribution of main water types, using groundwater samples. 


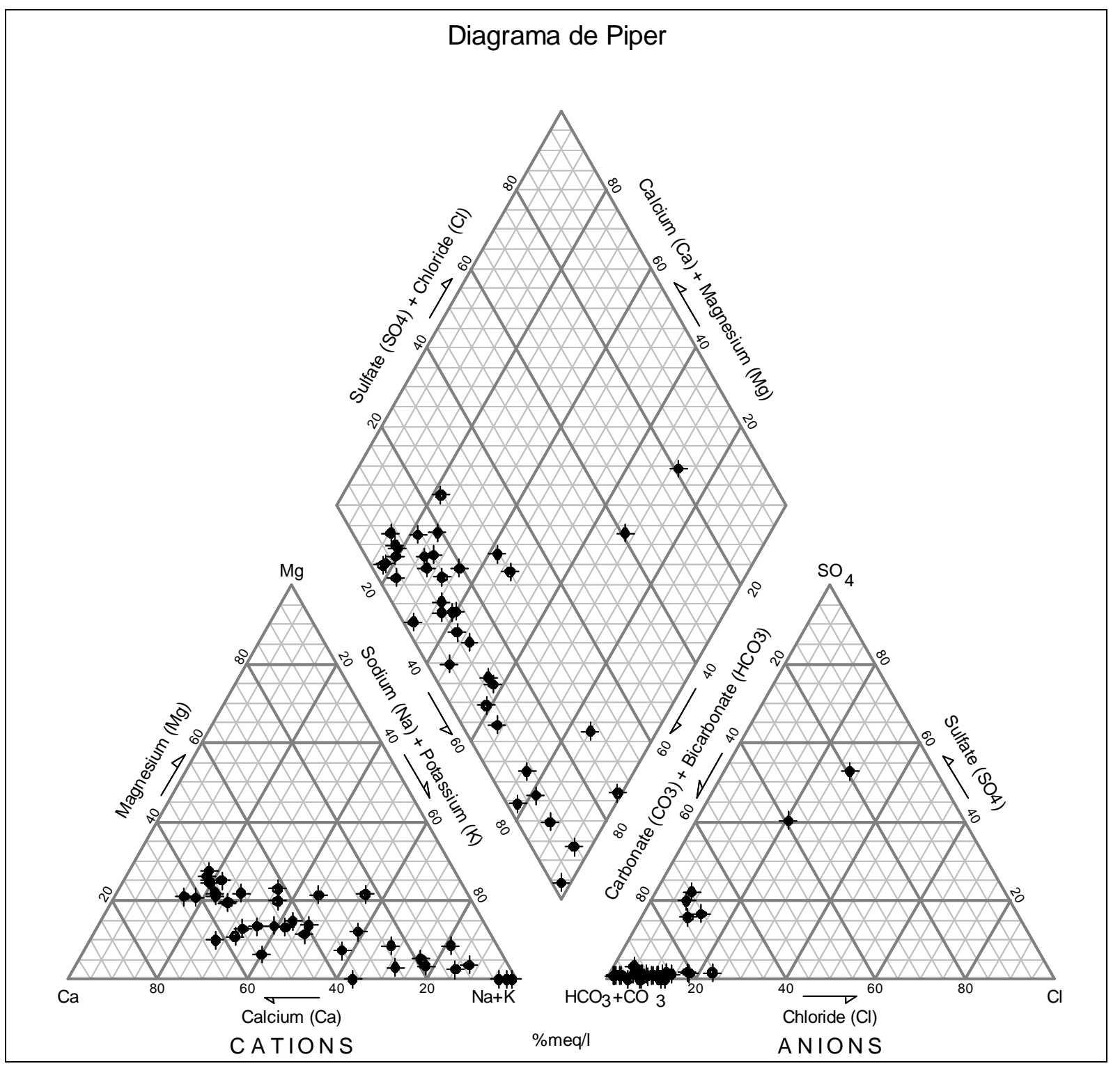

Figura 3 - Diagrama de Piper com 34 amostras de água subterrânea.

Figure 3 - Piper diagram with 34 groundwater samples.

O teor médio de bicarbonato é $84 \mathrm{mg} / \mathrm{L}$, com mediana $88,7 \mathrm{mg} / \mathrm{L}$. Os teores de cálcio variaram entre 0,8 e $33,7 \mathrm{mg} / \mathrm{L}$, com 16,2 de média e 17,2 a mediana.

Poços com elevados teores / valores de STD, Temperatura $\left({ }^{\circ} \mathrm{C}\right)$, condutância específica, $\mathrm{pH}$, potássio, sílica e fluoreto predominam nos municípios de Pato Bragado e Entre Rios do Oeste. Destaca-se também um poço situado em MCR, cujos teores acima mencionados se assemelham a amostra coletada no poço tubular existente no município, que capta o Aqüífero Botucatu.

A ocorrência de águas sulfatadas bicarbonatadas sódicas, bicarbonatadas sódicas e carbonatadas sódicas no ASG pode estar relacionada a contribuição de águas do aqüífero Guarani (mais ricas em sulfato, sódio e cloreto).
A figura 4 apresenta a distribuição espacial dos tipos de água classificados.

A tabela 1 apresenta as concentrações médias e as medianas dos sete tipos de água classificados.

\section{APROVEITAMENTO DAS ÁGUAS DO ASG PARA IRRIGAÇÃO}

O uso da água subterrânea para irrigação é limitado pelos efeitos adversos ao solo e plantas, relacionados à presença de substâncias dissolvidas na água, associados à salinidade total da água e ao conteúdo de sódio em solução.

A água com conteúdo elevado de STD causa "risco de salinidade" sendo tóxicas para as plantas. Concentrações elevadas de sólidos dissolvidos no solo podem causar uma condição de seca fisiológica, na qual, apesar do solo estar úmido a planta irá murchar, pois as raízes não 


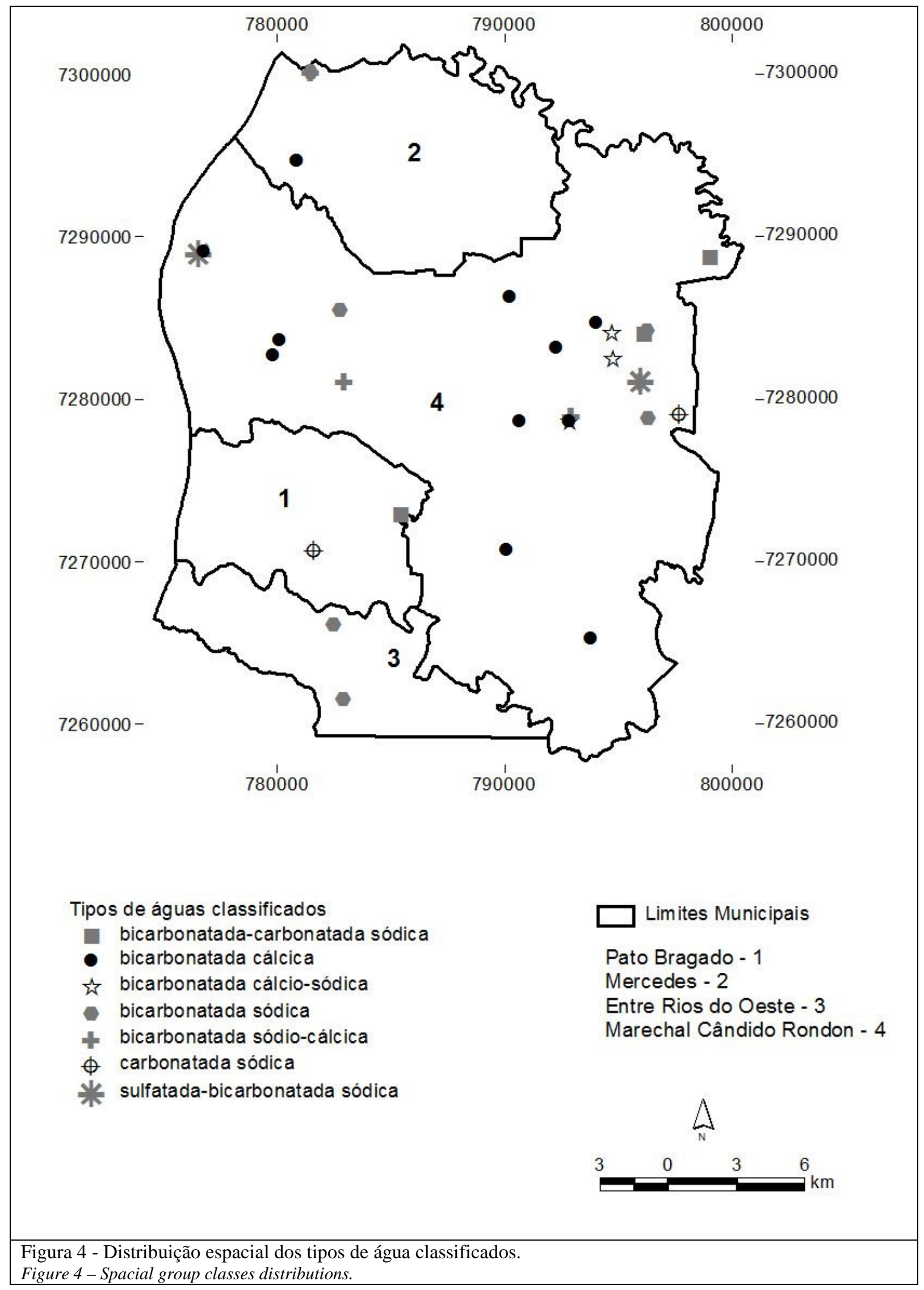


Tabela 1 - Concentrações médias e medianas das águas: bicarbonatada cálcica, bicarbonatada sódica, bicarbonatada magnesiana, bicarbonatada-cloretada e cloretada-bicarbonatada magnesiana-sódica.

Table 1-Mean water concentrations for each one of four classes.

\begin{tabular}{|c|c|c|c|c|c|c|c|c|}
\hline \multirow{2}{*}{$\begin{array}{l}\text { TIPOS DE } \\
\text { ÁGUAS }\end{array}$} & \multicolumn{2}{|c|}{$\begin{array}{l}\text { Bicarbonatada } \\
\text { cálcica }\end{array}$} & \multicolumn{2}{|c|}{$\begin{array}{l}\text { Bicarbonatada } \\
\text { sódica }\end{array}$} & \multicolumn{2}{|c|}{$\begin{array}{l}\text { Bicarbonatada } \\
\text { sódica-cálcica }\end{array}$} & \multicolumn{2}{|c|}{$\begin{array}{l}\text { Bicarbonatada } \\
\text { cálcica-sódica }\end{array}$} \\
\hline & Média & Mediana & Média & Mediana & Média & Mediana & Média & Mediana \\
\hline Turbidez (UT) & 0,45 & 0,41 & 0,43 & 0,46 & 0,38 & 0,42 & 0,33 & 0,32 \\
\hline Cor (uH) & 0,71 & 0,00 & 0,83 & 0,00 & 0,50 & 0,00 & 0,00 & 0,00 \\
\hline $\begin{array}{r}\text { Condutividade } \\
(\square \mathrm{Scm} / \mathbf{s})\end{array}$ & 118,54 & 88,25 & 161,78 & 136,45 & 143,04 & 145,60 & 114,10 & 105,30 \\
\hline pH & 7,54 & 7,64 & 8,78 & 8,78 & 7,75 & 7,96 & 7,32 & 7,42 \\
\hline Dureza (mg/L) & 70,26 & 75,15 & 24,18 & 17,51 & 63,72 & 63,00 & 65,67 & 64,00 \\
\hline STD (mg/L) & 70,57 & 41,50 & 97,33 & 64,50 & 76,20 & 63,00 & 53,67 & 50,00 \\
\hline $\mathrm{SiO}_{2}^{-}(\mathrm{mg} / \mathrm{L})$ & 36,61 & 35,42 & 34,68 & 34,16 & 33,37 & 33,18 & 34,86 & 34,15 \\
\hline $\mathrm{HCO}_{3}^{-}(\mathrm{mg} / \mathrm{L})$ & 87,54 & 88,84 & 93,73 & 96,02 & 99,71 & 96,72 & 85,63 & 91,52 \\
\hline $\mathrm{CO}_{3}{ }^{2-}(\mathrm{mg} / \mathrm{L})$ & 0,45 & 0,00 & 14,77 & 16,64 & 0,00 & 0,00 & 0,00 & 0,00 \\
\hline $\mathrm{Cl}^{-}(\mathrm{mg} / \mathrm{L})$ & 5,36 & 5,35 & 4,52 & 4,50 & 6,63 & 6,00 & 7,00 & 7,00 \\
\hline$F^{-}(\mathrm{mg} / \mathrm{L})$ & 0,12 & 0,12 & 0,18 & 0,18 & 0,33 & 0,17 & 0,08 & 0,08 \\
\hline $\mathrm{SO}_{4}{ }^{2-}(\mathrm{mg} / \mathrm{L})$ & 0,82 & 1,00 & 0,67 & 0,75 & 7,54 & 1,00 & 1,00 & 1,00 \\
\hline $\mathrm{NO}_{3}^{-}(\mathrm{mg} / \mathrm{L})$ & 1,50 & 1,50 & 0,78 & 0,75 & 1,10 & 0,90 & 1,63 & 1,50 \\
\hline $\mathrm{Ca}^{2+}(\mathrm{mg} / \mathrm{L})$ & 21,35 & 22,04 & 6,73 & 6,41 & 19,31 & 19,20 & 18,53 & 18,00 \\
\hline $\mathrm{Mg}^{2}+(\mathrm{mg} / \mathrm{L})$ & 4,20 & 4,26 & 2,20 & 0,85 & 4,16 & 3,89 & 4,70 & 4,62 \\
\hline $\mathrm{Na}^{+}(\mathrm{mg} / \mathrm{L})$ & 10,85 & 10,45 & 43,57 & 44,60 & 24,26 & 26,00 & 17,60 & 17,00 \\
\hline $\mathrm{K}^{+}(\mathrm{mg} / \mathrm{L})$ & 0,49 & 0,51 & 0,38 & 0,32 & 0,52 & 0,41 & 0,47 & 0,50 \\
\hline $\begin{array}{r}\text { Ferro total } \\
(\mathrm{mg} / \mathrm{L})\end{array}$ & 0,02 & 0,01 & 0,07 & 0,02 & 0,02 & 0,02 & 0,02 & 0,01 \\
\hline \multirow[t]{2}{*}{$\begin{array}{l}\text { TIPOS DE } \\
\text { ÁGUAS }\end{array}$} & \multicolumn{2}{|c|}{$\begin{array}{l}\text { Bicarbonatada- } \\
\text { carbonatada } \\
\text { sódica }\end{array}$} & \multicolumn{2}{|c|}{$\begin{array}{c}\text { Sulfatada- } \\
\text { bicarbonatada } \\
\text { sódica }\end{array}$} & \multicolumn{2}{|c|}{$\begin{array}{l}\text { Carbonatada } \\
\text { sódica }\end{array}$} & & \\
\hline & Média & Mediana & Média & Mediana & Média & Mediana & & \\
\hline Turbidez (UT) & 0,37 & 0,35 & 1,26 & 1,26 & 0,39 & 0,39 & & \\
\hline Cor $(\mathbf{u H})$ & 0,83 & 0,00 & 3,0 & 3,0 & 1,25 & 1,25 & & \\
\hline $\begin{array}{r}\text { Condutividade } \\
(\square \mathrm{Scm} / \mathrm{s})\end{array}$ & 165,57 & 84,30 & 104,05 & 104,05 & 347,45 & 347,45 & & \\
\hline pH & 8,71 & 8,52 & 8,04 & 8,04 & 9,63 & 9,63 & & \\
\hline Dureza (mg/L) & 24,56 & 24,00 & 78,00 & 78,00 & 4,27 & 4,27 & & \\
\hline STD (mg/L) & 99,33 & 40,00 & 123,00 & 123,00 & 205,00 & 205,00 & & \\
\hline $\mathrm{SiO}_{2}^{-}(\mathrm{mg} / \mathrm{L})$ & 34,91 & 30,53 & 32,65 & 32,65 & 31,25 & 31,25 & & \\
\hline $\mathrm{HCO}_{3}^{-}(\mathrm{mg} / \mathrm{L})$ & 54,01 & 45,76 & 73,49 & 73,49 & 55,13 & 55,13 & & \\
\hline $\mathrm{CO}_{3}{ }^{2-}(\mathrm{mg} / \mathrm{L})$ & 17,11 & 16,64 & 4,08 & 4,08 & 62,12 & 62,12 & & \\
\hline $\mathrm{Cl}^{-}(\mathrm{mg} / \mathrm{L})$ & 5,78 & 5,00 & 40,50 & 40,50 & 13,04 & 13,04 & & \\
\hline $\mathrm{F}^{-}(\mathrm{mg} / \mathrm{L})$ & 0,15 & 0,15 & 0,26 & 0,26 & 0,35 & 0,35 & & \\
\hline $\mathrm{SO}_{4}{ }^{2-}(\mathrm{mg} / \mathrm{L})$ & 8,93 & 0,00 & 105,00 & 105,00 & 19,05 & 19,05 & & \\
\hline $\mathrm{NO}_{3}^{-}(\mathrm{mg} / \mathrm{L})$ & 1,10 & 1,10 & 0,30 & 0,30 & 0,90 & 0,90 & & \\
\hline $\mathrm{Ca}^{2+}(\mathrm{mg} / \mathrm{L})$ & 8,69 & 8,41 & 25,65 & 25,65 & 1,41 & 1,41 & & \\
\hline $\mathrm{Mg}^{2}+(\mathrm{mg} / \mathrm{L})$ & 0,70 & 0,72 & 3,40 & 3,40 & 0,18 & 0,18 & & \\
\hline $\mathrm{Na}^{+}(\mathrm{mg} / \mathrm{L})$ & 32,70 & 20,00 & 82,50 & 82,50 & 90,00 & 90,00 & & \\
\hline $\mathrm{K}^{+}(\mathrm{mg} / \mathrm{L})$ & 0,43 & 0,44 & 0,42 & 0,42 & 0,38 & 0,38 & & \\
\hline $\begin{array}{r}\text { Ferro total } \\
(\mathrm{mg} / \mathrm{L})\end{array}$ & 0,01 & 0,01 & 0,01 & 0,01 & 0,02 & 0,02 & & \\
\hline
\end{tabular}


conseguirão absorver água. A concentração de sólidos totais dissolvidos, às vezes denominada salinidade total, pode ser medida indiretamente

O diagrama da figura 5 mostra a qualidade da água para irrigação utilizando as amostras de água subterrânea coletadas nos poços tubulares. Das 34 amostras nota-se que:

- 10 poços têm risco nulo $(\mathrm{C} 0-\mathrm{S} 1)$ com valores de condutividade abaixo de 100 $\mu \mathrm{S} / \mathrm{cm}$. Devido a escala do gráfico estas amostras não estão representadas.

- 18 poços têm riscos de sódio baixo e risco de salinidade baixo (C1-S1).

- Seis poços possuem valores de sódio ou salinidade que indicam restrições. Estes poços estão distribuídos da seguinte maneira:

- Um poço, localizado no município de Pato Bragado tem risco de médio sódio e baixo risco de salinidade (C1-S2). pelo valor da condutividade elétrica da água, já que estas duas grandezas são linearmente dependentes (ROSA FILHO; HINDI, 2006).

- Um poço em Entre Rios do Oeste tem risco de sódio médio e risco de salinidade médio (C2-S2).

- Dois poços têm risco de salinidade médio (C2-S1). Um localizado em MCR, na bacia do rio Ajuricaba e outro em Pato Bragado.

- Um poço em MCR com condutividade igual a $1479 \mu \mathrm{S} / \mathrm{cm}$ tem risco de salinidade alto (C3- S1).

- Um poço em Pato Bragado com 123 $\mathrm{mg} / \mathrm{L}$ de sódio, tem risco de sódio muito forte e médio risco de salinidade (C2S4). Neste caso o valor de Razão de Adsorção de sódio é 33,8. Uma vez que o limite de representação gráfica é 30 , esta amostra não é representada no gráfico.

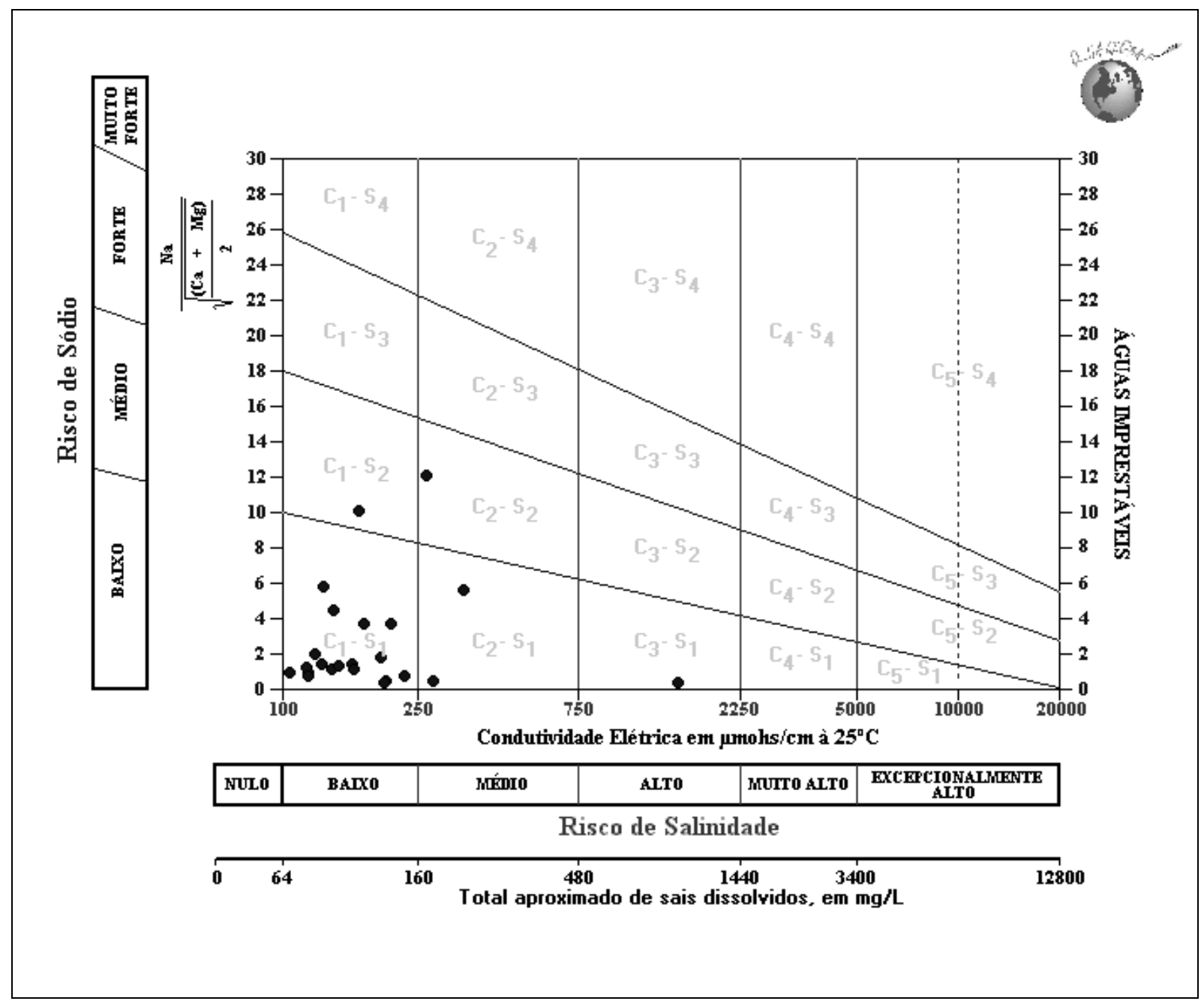

Figura 5 - Diagrama de classificação de água para irrigação.

Figure 5 - Diagram demonstrating the water classification for irrigation. 


\section{MISTURA DE ÁGUAS ENTRE O ASG E AQUIFERO BOTUCATU}

$\mathrm{Na}$ área de estudo, conforme apresentado, predominam poços com águas do tipo bicarbonatadas cálcicas. Entretanto, nos municípios de Marechal Cândido Rondon, Pato Bragado e Entre Rios do Oeste, poços tubulares que captam o Aqüífero Serra Geral apresentam tipologias químicas como sulfatadas bicarbonatadas sódicas e carbonatadas sódicas, bastante diferenciadas do padrão bicarbonatada cálcica.

Nesta abordagem específica, foram selecionados apenas quatro poços do ASG que apresentaram tipologia química diferenciada do padrão regional e um poço que capta o aquífero Botucatu, situado em MCR, para comparação.

Os poços são assim identificados:

- Poço 01 BOTUCATU: Localizado em MCR, capta o aqüífero Botucatu.

- Poço 02 (MCR): localizado em MCR, capta o ASG.

- Poço 03 (MCR 1): localizado em MCR, capta o ASG.

- Poço 04 (PB): localizado em Pato Bragado, capta o ASG.

- Poço 05 (PB 1): localizado em Pato Bragado, capta o ASG.

As características hidrodinâmicas dos poços aqui utilizados são descritas na tabela 2 . Ressalta-se, nos poços aqui destacados, o nível potenciométrico (virtual) do aqüífero Botucatu, acima da potenciometria regional do ASG.

Tabela 2 - Parâmetros hidrodinâmicos dos poços utilizados

Table 2 - Hydrodinamics features in groundwater wells.

\begin{tabular}{c|c|c|c}
\hline Código & $\begin{array}{c}\text { Cota } \\
\text { (m.s.n.m.) }\end{array}$ & $\begin{array}{c}\text { Nível } \\
\text { Estático } \\
(\mathrm{m})\end{array}$ & $\begin{array}{c}\text { Cota } \\
\text { Potenciométrica } \\
\text { (m.s.n.m.) }\end{array}$ \\
\hline $\begin{array}{c}\text { Poço 01 - } \\
\text { BOTUCATU }\end{array}$ & 395 & $-91,5$ & 303,5 \\
\hline $\begin{array}{c}\text { Poço 02 - } \\
\text { MCR (ASG) }\end{array}$ & 392 & $-94,0$ & 298,0 \\
\hline $\begin{array}{c}\text { Poço 03 - } \\
\text { MCR 1 } \\
\text { (ASG) }\end{array}$ & 303 & $-21,8$ & 281,2 \\
\hline $\begin{array}{c}\text { Poço 04 - } \\
\text { PB (ASG) }\end{array}$ & 228 & $-5,0$ & 223,0 \\
\hline $\begin{array}{c}\text { Poço 05 - PB } \\
\text { 1 (ASG) }\end{array}$ & 245 & $-33,7$ & 211,3
\end{tabular}

\section{TIPOLOGIA QUÍMICA DO AQÜÍFERO BOTUCATU (AQÜÍFERO GUARANI) NO OESTE PARANAENSE}

Na região oeste do Estado do Paraná são poucos os poços perfurados até o Aqüífero Botucatu. Isto se deve principalmente a dois fatores: a espessura de até 920 metros de basaltos (Formação Serra Geral) e o alto teor de íons dissolvidos na água subterrânea, condicionando sua aplicação principal à industria do turismo de águas termais.

Os três poços tubulares profundos que captam o Aqüífero Botucatu (MCR, Itaipulândia e Foz do Iguaçu) aqui utilizados, são os mais próximos a área de estudo, e apresentam a seguinte tipologia química:

- Marechal Cândido Rondon: água sulfatada sódica.

- Itaipulândia: água sulfatada sódica.

- Foz do Iguaçu: cloretada-sulfatada sódica.

Os poços de Marechal Cândido Rondon, Itaipulândia e Foz do Iguaçu são apresentados no diagrama de Piper da figura 6.

\section{RELAÇÕES POTENCIOMÉTRICAS E MISTURAS DE ÁGUAS ENTRE OS AQÜIIFEROS SERRA GERAL E BOTUCATU}

Neste estudo foi utilizado o poço de Marechal Cândido Rondon (Poço 01 BOTUCATU) para correlação química e potenciométrica entre os aqüíferos em função da proximidade com os poços do ASG estudados.

Ressalta-se que, a potenciometria regional do aqüífero Botucatu, na região oeste paranaense, nos outros dois poços tubulares (Itaipulândia e Foz do Iguaçu) se mantém acima da cota potenciométrica regional do ASG, destacando o artesianismo existente no poço situado em Foz do Iguaçu, utilizado a mais de dez anos no turismo termal.

Para analisar a relação potenciométrica entre os aqüíferos, na região de estudo, foi confeccionado um perfil hidrogeológico esquemático (Figura 7) entre os poços selecionados, desde MCR até Pato Bragado.

Observa-se que a cota potenciométrica do Aqüífero Botucatu (poço em MCR), está acima da cota altimétrica dos poços situados no município de Pato Bragado (PB e PB 1), evidenciando a possibilidade hidráulica de conectividade entre os aquíferos. Ressalta-se que em função da compartimentação estrutural do ASG trata-se de um nível potenciométrico "virtual". 


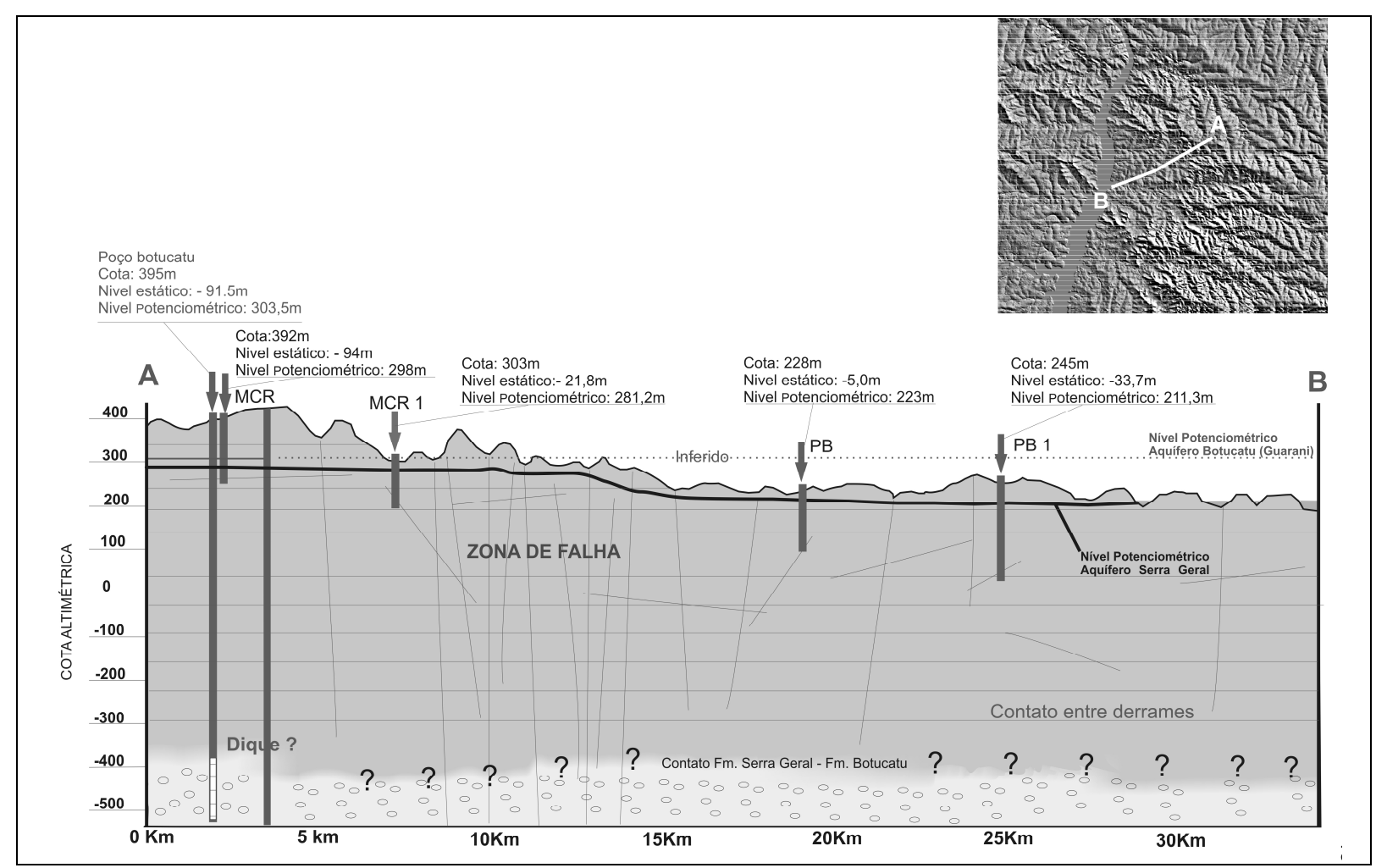

Figura 7 - Perfil hidrogeológico esquemático.

Figure 7 - Hydrogeologic cross section

A relação potenciométrica entre os aqüíferos contribui para explicar os teores "anômalos" ao ASG, principalmente para os íons sulfato e sódio.

Os poços apresentados no perfil hidrogeológico esquemático podem apresentar quimismo diferenciado do tipo bicarbonatada cálcica em função da mistura de águas entre os aqüíferos Serra Geral e Botucatu. Entretanto, não podem ser descartadas a possibilidade de quimismos diferenciados, dentro do ASG, em função principalmente de litotipos mais alcalinos, ou até mesmo contribuições de outros aqüíferos sotopostos ao Aqüífero Botucatu.

A hipótese de mistura de águas entre os ASG e Botucatu, neste caso, parece mais apropriada, em função das tipologias químicas entre os dois aqüíferos.

Corrobora esta afirmação a possibilidade de amostragem do Aqüífero Botucatu nos poços situados em MCR, Itaipulândia e Foz do Iguaçu para classificação química das águas e obtenção dos dados hidrodinâmicos aqui apresentados.

Destaca-se também que a temperatura da água nos poços onde há mistura de águas está acima da média para o ASG, evidenciando inclusive efeito do termalismo do aquífero Botucatu no ASG.

\section{CONCLUSÕES}

Foram classificados na área de estudo, segundo os íons predominantes, sete tipos principais de água no ASG: bicarbonatada cálcica $(43,6 \%)$; bicarbonatada sódica $(17,9 \%)$; bicarbonatada sódica-cálcica (12,8\%); bicarbonatada cálcica-sódica (7,7\%); bicarbonatada-carbonatada sódica (7,7\%); carbonatada sódica $(5,1 \%)$; sulfatadabicarbonatada sódica $(5,1 \%)$.

Alguns tipos químicos destacam-se por diferenciarem do padrão bicarbonatada cálcica existente no Aqüífero Serra Geral, estas "anomalias físico-químicas" em função da semelhança com o tipo químico das águas do aquífero Botucatu (em sua área de confinamento), e também pela relação potenciométrica local (que indica ascensão do fluxo do aquifero Botucatu em direção ao ASG), sugere que ocorram misturas de águas entre os aqüíferos, no município de MCR e limítrofes aqui abordados.

Corrobora esta afirmação a temperatura mais elevada dos poços onde há mistura de águas. Como exemplos, os poços localizados no município de Entre Rios do Oeste com temperatura de $27^{\circ} \mathrm{C}$ e Pato Bragado com 25,6 ${ }^{\circ} \mathrm{C}$. 
Ressalta-se que o fluxo entre aquífferos dá-se principalmente por falhas com altos ângulos de mergulho e/ou pelas intrusões dos diques de diabásio, estes fatos destacam a importância do mapeamento destas estruturas, bem como um detalhamento e controle das mesmas em campo quando da locação de poços tubulares profundos.

Deve destacar a dificuldade de mapeamentos destas estruturas que conectam ambos os aqüíferos em função principalmente da anisotropia estrutural do ASG, que faz com que coexistam lado a lado poços tubulares com teores diferenciados e poços com o padrão químico predominante neste aquiífero.

Dentre as amostras coletadas, quando comparadas a valores orientadores, as águas do ASG geralmente não apresentam restrições para consumo humano ou irrigação in natura, o que representa o potencial deste aqüífero para a região.

Excetuam-se seis poços, restritos à irrigação em função de elevados teores de sódio e condutividade. Para consumo in natura, excetuam-se dois poços, um situado em MCR e outro em Pato Bragado, que apresentam valores de fluoreto e $\mathrm{pH}$ (respectivamente) acima dos valores máximos permitidos pela Portaria $\mathrm{n}^{\circ} 518$ do Ministério da Saúde (BRASIL, 2004).

Frente aos teores elevados encontrados nas águas do aquifero Botucatu, na área de estudo, quando ocorrem condições favoráveis à comunicação entre os aqüíferos, muitas vezes as águas do ASG acabam por perder qualidade, tanto para consumo in natura, quanto para irrigação, em função do aumento na concentração dos teores.

Em função de suas restrições químicas para consumo in natura, outra possibilidade de utilização das águas do Aqüífero Botucatu, na área de estudo, dá-se pelo termalismo de suas águas, favorecendo a instalação de empresas focadas no turismo termal.

O ASG deve ser encarado como importante recurso hídrico, em especial na região de MCR, em função de sua qualidade e aptidão para o consumo in natura, bem como pela possibilidade de suprir a demanda de irrigação em períodos prolongados de estiagem. 


\section{REFERÊNCIAS}

BITTENCOURT, A.V.L.; ROSA FILHO, E.F.; HINDI, E.C.; BUCHMANN FILHO, A.C. A influencia dos basaltos e de misturas com águas de aquíferos sotopostos nas águas subterrâneas do sistema aqüífero Serra Geral, na bacia do rio Piquiri, Paraná, BR. Águas Subterrâneas. Curitiba: ABAS, v. 17, p. 67-75, 2003.

BRASIL. Ministério da Saúde. Portaria no 518 de 25 de março de 2004. Estabelece normas e o padrão de potabilidade da água destinada ao consumo humano. Diário Oficial da União, Brasília, v. 59, p. 266-270, 26 mar., Seção 1. 2004.

BUCHMANN FILHO, A.C. Características das águas subterrâneas do Sistema Aquífero Serra Geral no Estado do Paraná. Curitiba, 120p. Dissertação (Mestrado em Geologia Ambiental) Departamento de Geologia, UFPR. 2002.

FERNANDES, A.J.; , C.; WAHNFRIED, I.; FERREIRA, L.M.R.; PRESSINOTTI, M.M.N.; VARNIER, C.; IRITANI, M.A.; HIRATA, R. Modelo conceitual preliminar de circulação de água subterrânea do aquífero Serra Geral, Ribeirão Preto, SP. In: XIV Congresso Brasileiro de Águas Subterrâneas da ABAS., 2006. Anais do XIV Congresso Brasileiro de Águas Subterrâneas, 2006.

MELFI, A.J.; PICCIRILLO, E.M. ; NARDY, A.J.R. Geological and magmatic aspects of the Parana Basin: an introduction. In: PICCIRILLO E.M. e MELFI, A.J. (Eds.). The Mesozoic Flood Volcanism of the Parana Basin: petrogenetic and geophysical aspects. São Paulo: USP, p. 1-14. 1988.

PARANÁ. Superintendência de Desenvolvimento de Recursos Hídricos e Saneamento Ambiental. Banco de dados georreferenciados de poços tubulares profundos. Curitiba, 2005.
PEATE D.W.; HAWKESWORTH C.J.; MANTOVANI M.S.M. Chemical Stratigrafhy of Paraná Lavas (South America): Classification of Magma Types and their Spatial Distribuition. Bull. Volcanol, 55: 119-139.; 1992.

PIPER, A.M. A graphic procedure in the geochemical interpretation of water-analyses. Transactions of the American Geophysical Union - 1944. Washington (DC), Part VI, p. 914-928, May/1945.

ROSA FILHO, E.F.; BITTENCOURT, A.V.L.; SALAMUNI, R. Contribuição ao estudo das águas subterrâneas nos basaltos no Estado do Paraná. Boletim Paranaense de Geociências, n.37, p. 22-41, 1987.

ROSA FILHO, E.F.; HINDI, E.C. Diagnóstico das águas subterrâneas no Estado do Paraná: quantidade e qualidade. Relatório técnico. 2006.

U.S. SALINITY STAFF. Diagnosis and improvmente of saline and alkali soils. U. S. Department of agriculture; Agriculture Handbook, n. 60, 160p. Washington, DC, 1954.

WHITE, I.C. Relatório Final da Comissão de Estudos das Minas de Carvão de Pedra do Brasil. Rio de Janeiro: DNPM, 1988. Parte I; Parte II, p. 301617. (ed. Fac-similar); 1906.

\section{AGRADECIMENTOS}

Os autores agradecem a Itaipu Binacional pela concessão dos dados e financiamento do projeto de pesquisa "Estudos Hidrogeológicos na Bacia Hidrográfica do Paraná III". Específico ao diretor Nelton Friedrich e a bióloga Simone Benassi, pelo apoio e oportunidade. 